\title{
Measuring organizational commitment of varsity athletes in NCAA
}

\author{
Keunsu Han, Kyoung Tae Kim ${ }^{\mathbf{b}}$, Jaehyun $\mathrm{Ha}^{\mathbf{c}^{*}}$ \\ ${ }^{a}$ Associate Professor, Department of Kinesiology, Towson University, Towson, MD, USA \\ ${ }^{b}$ Assistant Professor, School of Health and Human Performance, Kean University, Union, NJ, USA \\ ${ }^{c}$ Associate Professor, Department of Sport Marketing, Keimyung University, Daegu, Republic of Korea
}

\begin{abstract}
The objective of this study was to confirm the multidimensionality of varsity athletes' commitment in NCAA Division I and Division II. A secondary purpose of this study was to examine the differences of commitment between Division I and Division II varsity student athletes. The instrument by Turner (2001) was revised in order to measure that commitment. The scale consisted of four bases of commitment including Affective Commitment (AC), Normative Commitment (NC), Continuance Commitment-High Sacrifice (CC-HiSac), and Continuance Commitment-Low Alternative (CC-LoAlt). A total of two hundred thirty five (235) varsity athletes in Division I and II participated in the survey. A Confirmatory Factor Analysis (CFA) was conducted to access the measurement model of athletes' commitment and a multivariate analysis of variance (MANOVA) was conducted to investigate the differences of commitment between Division I and Division II varsity student athletes. The CFA results indicated that the overall fit of the four bases measurement model was adequate. Overall, MANOVA was statistically significant. In a follow-up univariate test, there were significant differences in the "Affective," "Normative" and CC:LoAlt" bases. Division I varsity athletes were more committed to "Affective" and "Normative" factors, while "CC:LoAlt" was a more important commitment for Division II varsity athletes.
\end{abstract}

Key words: varsity athletes, college sports, athlete commitment, commitment scale

\section{Introduction}

Intercollegiate athletic programs not only have become an integral part of universities, but they also have evolved into a multibillion-dollar business (Weight, Jensen, \& Osborne, 2020). Although all collegiate sports do not create economic profits, the many other benefits to colleges have far-reaching

Submitted : 18 March 2021

Revised : 9 May 2021

Accepted : 31 May 2021

Correspondence: jaehyunha@kmu.ac.kr implications for students, faculty and the community. Athletic programs encourage school spirit, drive enrollment, strengthen bonds between the university and community, and heighten institutional reputations, often resulting in positive media attention (Vanover \& DeBowes, 2013). The success of intercollegiate athletics has also been considered a crucial communication tool that enhances an institution's publicity and university profile and increases private giving by alumni and community donors (Koo \& Dittmore, 2014).

Even though the commercialization of collegiate 
athletics has been criticized, the economic power of college athletics continues to grow (Turner \& Chelladurai, 2005). Athletes are primary sources of collegiate athletic programs and their performance directly influences the success of athletic programs. Raedeke (1997) stressed that the core element of athletes is their performance and qualified athletes' organizational commitment is a major concern for administrators. Therefore, understanding of the attitude of athletes is critical in that it directly relates to the effectiveness of their team and human resource management. From an organizational behavior perspective, employees are usually committed to an organization when there are positive works assigned and it (an organizatinal) has an attractive organizational environment (Safa, Ali, \& Ismail, 2018). This concept is similar to Meyer and Allen (1991) who attests that affective organizational commitment is defined by three major features: identification (e.g., confidence and recognition of the organization's goals and values), involvement (e.g., efforts to accomplish the organization's aim) and emotional bond (e.g., the desire to remain an organizational member).

Many studies on athlete's commitment have been conducted for intercollegiate coaches (Chellradurai \& Ogasawara, 2002; Cunnighan \& Sagas, 2004; Turner \& Chelladurai, 2005), however, there is little study about the organizational commitment of varsity athletes in the NCAA. Many researchers have examined the relationship between organizational commitment and other possible variables, such as personal characteristics, job satisfaction, performance and turnover intention (McGee \& Ford, 1987; Jaros, 1995; Hackett et al., 1994; Somers, 1993; Meyer \& Allen, 1997; Cuskelly et al., 1998; Safa, Ali, \& Ismail, 2018; Robinson, Magnusen, \& Kim, 2019). In addition, although the four bases commitment model has been proposed as an alternative against the shortcomings of Meyer and Allen's (1991) three-component commitment model, few studies have been conducted by using the four bases commitment model. Specifically, continuance commitment has been developed in clarifying the meanings of two seperate components, however, a generally accepted model of continuance commitment has yet to emerge in sport related research. Much of disagreement about the multiple continuance dimensions for the meaning of continuance commitment is still traceable to definitional and measurement problems. In spite of increased significance to measure continuance commitment, limited research has tried to address this issue. It has been considered that previous perspectives were not inclusive of all that was meant by continuance commitment and that one view was not likely to recognize as correct, given that this study can contribute to acquire more comprehensive understanding of continuance commitment in sport setting.

Therefore, the purpose of this study was to confirm the multidimensionality of athletes' commitment in NCAA Division I and Division II athletics. In addition, this study investigated the differences of commitment between Division I and Division II athletes.

\section{Review of Literature}

\section{Side-Bet Theory}

The research studies of organizational commitment have extensively been developed based on Becker's (1960) Side-Bet Theory. Becker's interest was in why a person performs a consistent behavior. He focused on extraneous interests, which are the consequences of participating in a social group, including such factors as money, time, effort, reward and connection with the organization. Becker believed that "commitment comes into being when a person, by making a side bet, links extraneous interests with a consistent line of activity" (p. 32). The side bets can be categorized as contribution to pension plans, development of organizational specific skills or status, or use of organizational benefits (Meyer \& Allen, 1984). For example, an employee may not leave his/her company in spite of an offer of better income by another company because the employee may 
want to receive the company's pension.

Even though Side-Bet Theory has contributed to conceptualizing organizational commitment, criticisms have emerged. Wallace (1997) defined side-bets as "anything of importance that an employee has invested, such as time, effort or money that would be lost or devalued at some cost to the employee, if he or she left the organization” (p. 728). Based on this conceptualization, Wallace criticized that Side-Bet Theory did not explicitly define commitment. Another important criticism from Cohen and Gattiker (1992) came from a meta-analysis of 50 studies using the side-bet theory, stating that side-bet indexes do not explain the significant amount of variance in organizational commitment. They stated that "side-bet indexes appear to have a stronger effect when it tries to predict calculative commitment than did either value-moral commitment or the 15 item overall commitment questionnaire” (p. 449).

\section{Organizational Commitment as the Affective Outcome}

Commitment is considered a critical element that determines the success of an organization. Brantley (1993) mentioned that organizational commitment is a vital factor in any effective organization and is crucial in achieving human resource capabilities. The significance of commitment results from enhancing an organization's achievement, productivity, and effectiveness (Alrowwad, Almajali, Masa'deh, \& Obeidat, 2019). According to Singh and Gupta (2015) commitment can be defined as the attachment, identification, or loyalty to the entity. Organizational commitment refers to "the strength of an individual's identification with and involvement in a particular organization” (Porter, Steer, Mowday, \& Boulian, 1974, p. 604). Many researchers have had different views regarding organizational commitment concerning affective and behavior outcomes. For example, it has been found that organizational commitment is related to an employee's age and tenure within an organization, but inversely related to education. (Mowday, Porter, \& Steer, 1982). In addition, the outcomes of organizational commitment are postulated as behavior and behavioral intentions such as job-performance including absenteeism, tardiness and turnover or turnover intention (Mowday et al., 1982). According to Mayer and Allen (1997), employees who are more committed have characteristics such as: higher job performance, higher organizational citizenship, more ethical behavior, less stress, less job displeasure and a diminished intent to leave. More recent research by Clungston (2000) indicated that commitment partially mediates the relationship between job satisfaction and turnover intention.

Few studies have been conducted in the area of intercollegiate athletes, although studies of organizational commitment have developed numerous conceptualizations and a definition of organizational commitment over the last 40 years (Meyer \& Allen, 1997). Similar to research results to other fields, sport related research also showed that the organizational commitment relates to other employee outcomes. For example, Cuskelly (1995) tried to examine the relationship commitment and group-level processes and reported a link between organizational commitment and committee functioning's five dimensions: decision-process, cohesion, conflict resolution, receptiveness and homogeneity. Kim, Hong, Magnusen and Rhee (2020) conducted a cross-cultural study on athletic commitment and found that both abusive and supportive leadership significantly related to athletic commitment through interactional justice. Winterstein (1998) investigated the commitment of head athletic trainers, and the techniques to describe the head athletic trainer's commitment to the organization. He found that continuing commitment were significantly lower than the affective and normative commitment. In addition, results showed Division I and Division II head athletic trainers demonstrated higher levels of normative commitment to their athletic departments and affective and normative commitment to their co-workers than their Division III head athletic trainers. Moreover, Turner and Chelladurai (2005) suggested that continuance commitment LoAlt was positively correlated with 
intentions to leave the organization.

\section{Overview of Organizational Commitment Scale}

Previous research has supported organizational commitment as a one-dimensional construct: conceptual discussions about definitions, types of and importance of organizational commitment in different organizational settings (Palupi, Cahjono, \& Satyawati, 2017; Yang \& Wei, 2018). The Organizational Commitment Questionnaire (OCQ) by Porter, Steer, Mowday, and Boulian (1974) has been the most utilized tool to measure organizational commitment (Clugston, Howell, \& Dorfman, 2000). The OCQ measures an individual's affective commitment to the organization (Becker, 1992; Hunt \& Morgan, 1994; O’Reilly \& Chatman, 1986). However, the OCQ has limitations in regards to the theoretical research of employee commitment because individuals make different commitments to their organizations than they do to their supervisors or peers (Reichers, 1985). Becker's (1992) test about Reichers' suggestion indicates that individual measures of commitment across multiple bases foci accounted for a unique variance in key dependent variables. Hunt and Morgan (1994) confirmed Becker's research. Moreover, Becker et al. (1996) confirmed again that there are distinctions between various commitment types employees make to their organization, supervisor, and peers.

Meyer and Allen (1991) developed a three-component organizational commitment instrument including affective, continuance, and normative commitment. According to Meyer and Allen, each of the three bases of commitment were also affected by different classes of antecedents. A direct effect on affective commitment could include work experience and personal characteristics. The cost related to leave the organization could affect continuance commitment. The social and cultural orientations of each employee could affect the normative commitment. Based on previous research (Meyer \& Allen, 1997; Jackson,
Gucciardi, \& Dimmock, 2014) developed a commitment instrument to examine affective, normative and continuance commitment with their coach, and to assess athletes' commitment to their teams.

Even though Meyer and Allen's three-component model is most often used, many researchers argue that continuance commitment is comprised of two separate dimensions (Hackett et al., 1994; McGee \& Ford, 1987; Meyer \& Allen, 1997; Somers, 1993). The two separate dimensions in commitment scale include CC:LoAlt (continuance commitment-low number of alternatives) and CC:HiSac (continuance commitment-high personal sacrifice). CC:LoAlt and CC:HiSac will be discussed below in detail.

Four bases model of organizational commitment

Organizational commitment has been a complex multidimensional construct to define (Hackett \& Lapierre, 2001; Shagholi, Zabihi, Atefi, \& Moayedi, 2011). Conceptualization of Meyer and Allen (1984) began by categorizing organizational commitment as two different factors: affective and continuance commitment. After continuous empirical research, they inserted normative commitment into their conceptualization of organizational commitment (Meyer \& Allen, 1991). Consequently, they divided organizational commitment into three separate dimensions: affective, normative, and continuance.

Affective commitment refers to "the employee's emotional attachment to identification with, and involvement in the organization. Employees with a strong affective commitment continue employment in the organization because they want to do so" (p. 67). For example, the degree to which an employee's values and goals parallel with the organizations is hypothesized to influence directly the employee's desire to stay in the organization.

Normative commitment refers to "the employee's feeling of obligation to continue employment. Employees with a high level of normative commitment 
feel that they ought to remain with the organization" (Meyer \& Allen, 1991, p. 67). For example, when employees have duty that ought to stay their organization, employees have normative commitment.

Continuance commitment refers to "awareness of the costs associated with leaving the organization. Employees whose primary link to the organization is based on continuance commitment remain because they need to do so" (Meyer \& Allen, 1991, p. 67). For example, when employees worry about a dearth of alternative jobs opportunities, employees tend to stay with their organization.

Based on this conceptualization, Meyer and Allen developed an instrument to measure three dimensions of organizational commitment. Even though this three-component instrument is often used today, there has been criticism of the three-component model. Many studies indicate that the continuance commitment was divided into two different factors (Hackett et al., 1994; McGee \& Ford, 1987; Meyer \& Allen, 1997; Somers, 1993). In sport related literature, Turner (2005) confirmed in his research regarding organizational commitment that continuance commitment could be split into two dimensions. He modified Meyer and Allen's (1991) continuance commitment into two seperate concepts and found continuance commitment consists of two seperate components. Two separate dimensions in the continuance commitment scale includes CC:LoAlt (Continuance commitment-low number of alternatives) and CC:HiSac (Continuance commitment-high personal sacrifice). CC:LoAlt is defined as a perceived lack of other variable employment opportunities, while CC:HiSac is defined as a loss by leaving the organization. For example, a student athlete may hesitate to transfer his/her dream school to play because he/she will not be guaranteed to secure a scholarship opportunity, which current school has provided. In this case, CC:HiSac can be applied. On the other hand, if a student athlete has no options to transfer even though he/she does not want to play in current school CC:LoAlt is conceptually appropriate. In conclusion, a modified four-dimensional scale includes: (1) Affective commitment, (2) Normative commitment, (3) Continuance commitment-Low number of alternatives, and (4) Continuance commitment-High personal sacrifice.

\section{The Level of Division in NCAA}

The Intercollegiate Athletic Association of the United States, now known as the National Collegiate Athletic Association (NCAA), formed in 1906. The NCAA is an organization dedicated to the well-being and success of student-athletes. Membership to the NCAA was divided into three divisions for competition and legislative purposes in 1973 and the inclusion of women's athletics in the 1980s was also structured into the NCAA (National Collegiate Athletic Association, 2010).

The NCAA is comprised of nearly half of a million student-athletes, 19,500 teams, and 52,500 organizers and coaches. The NCAA is divided into Divisions I, II and III. Division I is the most competitive level of athletics. Division I member institutions have to sponsor at least seven sports for men and seven for women (or six for men and eight for women) with two team sports for each gender. Division I schools must meet minimum financial aid awards for their athletic programs. There also are maximum financial aid awards for each sport (ncaa.org).

Division II is the second tier and have to sponsor at least five sports for men and five for women, (or four for men and six for women), with two team sports for each gender, and each playing season represented by each gender. Division II schools typically offer their students a good balance between competitive sporting events, community engagement, and academics. Approximately 62 percent of students at Division II schools receive some type of academic, athletic or need-based financial aid. There are maximum financial aid awards for each sport that a Division II school must not exceed. Division II teams usually feature a number of local or in-state student-athletes. Many Division II student-athletes pay for school through a combination of scholarship money, grants, student loans and employment earnings. Division II athletic programs are 
a part of the institution's budget like other academic departments (ncaa.org).

\section{Research Hypotheses}

Hypothesis 1: The bases of commitment for college student athletes include affective commitment, normative commitment, continuance commitment-high personal sacrifice, and continuance commitment-low number of alternatives.

Hypothesis 2: There are differences in the affective commitment between Division I and Division II athletes.

Hypothesis 3: There are differences in the normative commitment between Division I and Division II athletes.

Hypothesis 4: There are differences in the continuance commitment-high personal sacrifice between Division I and Division II athletes.

Hypothesis 5: There are differences in continuance commitment-low number of alternatives between Division I and Division II athletes.

\section{Methods}

\section{Participants}

A convenience sampling technique was used to select subjects for the study. The sample consisted of 235 varsity athletes in NCAA Division I and II schools in the U.S. (Division I: 127; Division II: 108). The authors utilized personal contacts to obtain a sample of varsity athletes from four different DII institutions and three separate DI institutions. With the permission of the coaches for an online survey, an invitation email was sent to all varsity athletes at each institution. The participants were assured that all information gathered would be held confidential, presented in group form and only used in this study. The invitation email included an informed consent statement and a link to the survey instrument. A reminder email was sent to each

Table 1. Demographic Characteristics

\begin{tabular}{|c|c|c|c|}
\hline Demographic Information & Classification & $\begin{array}{l}\text { Frequency } \\
(N=235)\end{array}$ & Percent (\%) \\
\hline \multirow{2}{*}{ Gender } & Male & 121 & 51.49 \\
\hline & Female & 114 & 48.51 \\
\hline \multirow{5}{*}{ Race } & Caucasian & 111 & 47.23 \\
\hline & African American & 93 & 39.57 \\
\hline & Hispanic & 17 & 7.23 \\
\hline & Asian & 9 & 3.83 \\
\hline & Other & 5 & 2.13 \\
\hline \multirow{5}{*}{ Academic Class } & Freshmen & 45 & 19.15 \\
\hline & Sophomore & 52 & 22.13 \\
\hline & Junior & 62 & 26.38 \\
\hline & Senior & 55 & 23.40 \\
\hline & Graduate & 21 & 8.94 \\
\hline \multirow{3}{*}{ Athletic Aid } & No & 7 & 2.98 \\
\hline & Yes, partial aid & 152 & 64.68 \\
\hline & Yes, full aid & 76 & 32.34 \\
\hline
\end{tabular}


student-athlete approximately three weeks following the initial invitation. A total of 883 varsity athletes invited to participate and 235 varsity athletes responded. A survey response rate for this study was $26.61 \%$.

With respect to gender, 121 of the respondents identified as male (51.49\%) and 114 identified as female (48.51\%). In terms of race, 111 respondents (47.23\%) were Caucasian, 93 (39.57\%) were Black, 17 were Hispanic (7.23\%), and 9 (3.83\%) were Asian. With regard to academic class, junior (26.38\%) were the most frequent responders. Freshmen made up $19.15 \%$ and $22.13 \%$ were sophomore. Senior represented $23.40 \%$ and graduate students accounted for $8.94 \%$. While only seven athletes (2.98\%) responded they do not have athletic aid, 228 respondents answered they have partial aid (64.68\%) or full aid (32.34\%) (see Table 1 ).

\section{Instrumentation}

In order to measure organizational commitment of varsity athletes in NCAA Division I and II, a four bases 12-item scale from Turner (2001) was modified. Existing scales were modified and some words and phrases were modified. A panel of experts was asked to examine thoroughly the questionnaires for content validity. A panel of experts included sport management professors $(n=3)$, current college coaches $(n=3)$, and individuals who had conducted research on organizational commitment in sports $(n=3)$. The final scale includes the four bases of commitment: (a) affective commitment (3 items), (b) normative commitment (3 items), (c) continuance commitment-high personal sacrifice (3 items), and (d) continuance commitment-low number of alternative (3 items). These items were modified to fit varsity athletes in college. The respondents were asked to indicate their level of agreement with each of the 12 items on a Likert scale, ranging from 1 (strongly disagree) to 5 (strongly agree). The reliability estimates (Chronbach's alpha) for these four bases were .81, .88, 75 , and .72, respectively and all values exceeded
Nunnally’s (1978) criteria of .70 .

\section{Data Analysis}

The data were analyzed using the Statistical Package for the Social Science (SPSSPC) and Analysis of Moment Structures (AMOS). In order to assess psychometric properties of the measures, confirmatory factor analyses (CFA) were conducted using the computer program Analysis of Moment Structures (AMOS). In addition, a multivariate analysis of variance (MANOVA) was conducted to investigate the differences of commitment between Division I and Division II varsity athletes.

\section{Results}

Multivariate Normality, Correlation, and Rank Order

Skewness and Kurtosis statistics were analyzed to determine normal distribution of data. Based on Kline's criteria (1998), data with absolute values in a univariate skewness index greater than 3.0 were considered to be extremely skewed. In addition, his criteria showed that absolute values of the univariate kurtosis index over 8.0 appear to be extreme kurtosis. All skewness and kurtosis values ranged from -1.492 to 2.227. Based on Kline's guideline, it was assumed that all variables in the data set achieved multivariate normality.

The correlation values among all variables were significantly correlated but they were distinct, indicating that there did not exist significant levels of multicollineaity because the correlation value between variables was less than .85 (Kline, 1998). The most important commitment of varsity athletes was "Affective" ( $\mathrm{M}=4.21)$ followed by "Normative" ( $\mathrm{M}=3.93)$, "Continuance commitment-low number of alternatives" ( $\mathrm{M}=3.38$ ) and "Continuance commitment-high sacrifice" $(\mathrm{M}=2.56)$. All mean comparisons were statistically significant $(p<.05)$ (see Table 2). 
Table 2. Rank Order of Varsity Athletes' Commitment

\begin{tabular}{cccc}
\hline \hline Factor & $N$ & $M$ & $S D$ \\
$\begin{array}{c}\text { 1. Affective } \\
\text { Commitment }\end{array}$ & 235 & 4.21 & .721 \\
$\begin{array}{l}\text { 2. Normative } \\
\text { Commitment }\end{array}$ & 235 & 3.93 & .782 \\
$\begin{array}{c}\text { 3. Continuance } \\
\text { Commitment-LoAlt }\end{array}$ & 235 & 3.38 & .871 \\
$\begin{array}{c}\text { 4. Continuance } \\
\text { Commitment-HiSac }\end{array}$ & 235 & 2.56 & .890 \\
\hline \hline
\end{tabular}

\section{Confirmatory Factor Analysis}

The first research question investigated whether the bases of commitment for intercollegiate athletes include affective commitment, normative commitment, continuance commitment-high personal sacrifice (CC:HiSac), and continuance commitment-low number of alternatives (CC:LoAl). The results of the measurement models are reported in Table 4. The overall fit indices for the CFA revealed that the measurement model fits the data well, showing that the measurement model adequately accounted for the covariance matrices of the data from the sample. The four-bases (affective, normative, continuance-high sacrifice and continuance-low number of alternatives) CFA model for athletes' commitment had 59 degrees of freedom. Results of the model fit indicated an acceptable model fit $\left(\chi^{2}[59]=155.3722 ; p<.05 ; \chi^{2} / d f=2.50 ;\right.$ CFI = .98; PNFI = .63; and RMSEA = .064). All of the model fit indices were satisfactory within the recommended thresholds.

As shown in Table 4, all standardized loadings were relatively high, ranging from .719 to .911 and statistically significant, indicating convergent validity for the four bases CFA model of varsity athletes' commitment. The value of average variance extracted (AVE) ranged from .58 to .74 and all exceeded the criteria of .50 by Fornell and Larker (1981). For discriminant validity, the estimated correlations between the four bases were from .301 to .638 (see Table 3), which is less than the
Table 3. Correlations among Four Bases

\begin{tabular}{lcccc}
\hline \hline & Affective & Normative & CC-HiSac & CC-LoAlt \\
Affective & 1 & & \\
Normative & $.429^{*}$ & 1 & 1 & \\
CC-HiSac & $.638^{*}$ & $.301^{*}$ & \\
CC-LoAlt & $.542^{*}$ & $.485^{*}$ & $.521^{*}$ & 1 \\
\hline \hline
\end{tabular}

recommended value of .85 (Kline, 1998).

\section{MANOVA}

The second, third, fourth and fifth research hypotheses examine whether there are any differences between Division I and Division II athlete's commitment depending on the four bases? The results of the Levene test indicated that the assumption of homescedasticity between groups was satisfactory $(F=$ .746, $p=.387$ ). The interaction of Division I and Division II on the bases of the athletes' commitment was significant (Wilks' ə = .730, $F=3.202, p=.041$ ). In a follow-up univariate test, there were significant commitment differences in "Affective," "Normative" and CC:LoAlt” bases. Division I athletes were more committed to their institutions due to "Affective" ( $F=$ 9.514, $p=.003)$ and "Normative" $(F=8.382, p=.007)$ reasons, while "CC:LoAlt” $(F=7.991, p=.013)$ was a more important commitment for Division II athletes. There was no significant relationship on "CC:HiSac" for Division I and II (see Table 5).

\section{Discussion and Conclusion}

This study supported a four bases measurement model, including CC:HiSac and CC:LoAlt for varsity athletes' commitment. In spite of the similar 
Table 4. Results of the CFA: Item Loading ( $\beta$ ), Standard Errors (SE), $t$-values (t), and Average Variance Extracted (AVE)

\begin{tabular}{lcccc}
\hline \hline \multicolumn{1}{c}{ Subscale } & $\beta$ & $S E$ & $t$ & AVE \\
\hline Affective & & & & .71 \\
I do not feel emotionally attached to my university (R) & .770 & .115 & 10.512 & \\
My university has a great deal of personal meaning for me & .827 & .091 & 10.190 \\
I do feel a strong of loyalty to my university & .775 & .126 & 10.185 \\
\hline
\end{tabular}

Normative

My university deserves my loyalty

$\begin{array}{lll}.891 \quad & 049 \quad 19.549\end{array}$

I owe a great deal to my university

$.911 \quad .081 \quad 15.970$

I would not leave my university right now because I have a sense of obligation to the people at it

$\begin{array}{lll}.777 \quad 082 & 15.430\end{array}$

\section{Continuance-HiSac}

It would be very hard for me to transfer from my university right now, even if I wanted to

.817

from my university right now

If I had not already invested so much of myself into my university, I might consider playing elsewhere

\section{Continuance-LoAlt}

Right now, staying at my university is a matter of necessity as much as desire

I believe that I have too few options to consider transferring from my university

One of the few negative consequences of transferring from my university would be the scarcity of available alternatives

$.071 \quad 14.788$

$\begin{array}{lll}.773 & .105 & 13.922\end{array}$

Table 5. MANOVA Results

\begin{tabular}{ccccc}
\hline \hline \multirow{2}{*}{ Factors } & $\begin{array}{c}\text { Division I } \\
(n=127)\end{array}$ & $\begin{array}{c}\text { Division II } \\
(n=108)\end{array}$ & $F$ & Sig. \\
\cline { 2 - 3 } & Mean (SD) & Mean (SD) & & \\
\hline 1. Affective & $4.52(.81)$ & $3.76(.71)$ & 9.514 & .003 \\
2. Normative & $4.11(.80)$ & $3.68(.82)$ & 8.382 & .007 \\
3. CC:HiSac & $2.66(.75)$ & $2.44(.69)$ & 0.158 & .661 \\
& & & & \\
4. CC:LoAlt & $2.98(.80)$ & $3.57(.80)$ & 7.991 & .013 \\
\hline \hline
\end{tabular}

characteristics of CC:HiSac and CC:LoAlt, the results satisfied the construct and discriminant validity. To support this result, it can be discussed that NCAA Division I and II athletes had two different kinds of continuance commitment. In other words, athletes can be both committed due to a low number of alternative college opportunities and high personal sacrifice in quitting the current school (i.e., scholarship, playing time).

By conducting an empirical analysis, the results of this study demonstrated that these four constructs fit the data fairly well, indicating that the measurements are 
psychometrically sound and appropriate for representing the concepts. Although the four bases commitment model was acceptable for varsity athletes, it is expected that other researchers may express a variety of views about the sub-dimensions and primary dimensions of athletes' commitment. This study has confirmed the conceptual validity of the four bases commitment model, including two separate continuance commitments. It is believed that the current study has added important implications to this area of study.

In addition, MANOVA was conducted to test the differences of organizational commitment between Division I and Division II varsity athletes. The results indicated that there were statistically significant differences in "Affective," "Normative" and "CC:LoAlt” commitment. Division I athletes were more committed than in Division II to their institutdue to "Affective" and "Normative" factors. Division II athletes were more committed for "CC:LoAlt" reasons. However, there was no statistically significant difference in "CC:HiSac" factors. Based on results of these differences, it might be said that Division I athletes were more committed than Division II athletes due to an emotional attachment to institutions. In other words, they appreciate the institution's values more and are willing to remain at their schools since they were highly recruited. On the other hand, Division II athletes were more committed to their institutions due to "CC:LoAlt." Division II athletes tend to remain at their institutions due to a perceived lack of other opportunities. The reliable and valid commitment scale developed for the study may serve as a valuable tool in understanding collegiate athletes, which will provide administrators with a basis for the existing commitment base.

Athletes are an integral part of collegiate athletic programs and their performance impacts economic and non-economic revenues. Improving varsity athletes' organizational commitment is usually a major concern for athletic departments because it directly relates to the effectiveness of their team and the reputation of the institution. Therefore, a clear understanding of the dynamics of an athlete's commitment is a critical component in both managing and increasing the potential revenues of an institution. With this knowledge, administrators can more effectively develop strategies and programs to both maintain and expand the commitment base.

\section{Limitation and Future Research}

The generality of the results in this study is limited to athletes from the sample of four universities including two in Division I and two in Division II. This study is a first attempt to conduct empirical tests in developing the measurement of athletes' four bases commitment. Some questions need to be answered regarding the findings of the study by using the same measures. Can the current findings be generalized to the population of college varsity athletes? Does the scale demonstrate reliability and validity when employing the sample from different universities and colleges? Due to the complexities of varsity athletes' commitment, it is recommended that future research should be undertaken with more diverse samples of college varsity athletes.

This study explained the differences between Division I and Division II varsity athlete's commitment. Future research efforts should also concern variables among demographic characteristics, such as age, gender, sexual orientation, family income, race and academic status, which may influence an athlete's commitment.

It is also possible to test various models associated with different variables, including satisfaction, involvement, stress, transfer intention, citizenship behavior, as well as organizational effectiveness. These diverse models will suggest ideas for athletic departments to retain qualified athletes and to maximize organizational effectiveness.

It is also a possibility that future studies can generate new items that will better represent the managerial factors of interest. The current study modified the items from previous research (Turner, 2001) in order to measure varsity athletes' commitment. It is possible for 
future research to contribute efforts in improving and refining the current scale items that may better capture the meanings associated with sub-dimensions in commitment construct.

Even though this study has endeavored to add some qualitative dimensions to the closed-form question, future studies should incorporate face-to-face interviews with athletes to confirm more clearly their commitment. The interviewer would provide an opportunity for the research to involve athletes in communication that could clarify the four bases of commitment.

\section{References}

Alrowwad, A., Almajali, D., Masa'deh, R., \& Obeidat, B. (2019). The role of organizational commitment in enhancing organizational effectiveness. Proceeding of the Education Excellence and Innovation Management, 9133-9154.

Becker, H. S. (1960). Notes on the concept of commitment. American Journal of Sociology, 66(1), 32-40.

Becker, T. E. (1992). Foci and bases of commitment: are they distinctions worth making? Academy of Management Journal, 35(1), 232-244.

Becker, T. E., Billings, R. S., Eveleth, D. M., \& Gilbert, N. L. (1996). Foci and bases of employee commitment: Implications for job performance. Academy of Management Journal, 39, 464-482.

Brantley, P. (1993). The many faces of commitment. Journal of Research on Christian Education, 2(1), 3-4.

Chelladurai, P., \& Ogasawara, E. (2003). Satisfaction and commitment of American and Japanese collegiate coaches. Journal of Sport Management, 17, 62-73.

Clugston, M., Howell, J., \& Dorfman, P. M. (2000). Does cultural socialization predict multiple bases and foci of commitment? Journal of Management, 26(1), 5-30.

Cohen, A. \& Gattiker, U. E. (1992). An empirical assessment of organizational commitment using the Side-Bet theory approach. International Labour Review, 47(3), 439-461.

Cunningham, G. B., \& Sagas, M. (2004). Group diversity, occupational commitment, and occupational turnover intentions among NCAA division IA football coaching staffs. Journal of Sport Management, 18, 236-254.

Cuskelly, G., McIntyre, N., \& Boag, A. (1998). A longitudinal study of the development of organizational commitment amongst volunteer sport administrators. Journal of Sport Management, 12(3), 181-202.

Fornell, C., \& Larcker, D. F. (1981). Evaluating structural models with unobservable variables and measurement error. Journal of Marketing Research, 18, 39-50.

Hackett, R., Bycio, P., \& Hausdorf, P. A. (1994). Further assessment of Meyer and Allen's 3-component model of organizational commitment. Journal of Applied Psychology, 79(1), 15-23.

Hackett, R.D., Lapierre, L.M., \& Hausdorf, P.A. (2001). Understanding the links between work commitments constructs. Journal of Vocational Behaviour, 58, 392-413.

Jackson, B., Gucciardi, D. F., Dimmock, J. A. (2014). Toward a multidimensional model of athletes' commitment to coach-athlete relationship and interdependent sport teams: a substantivemethodological synergy. Journal of Sport \& Exercise Psychology, 36, 52-68.

Jeros, S. J. (1995). An assessment of Meyer and Allen's (1991) three-component model of Organizational commitment and turnover intentions. Academy of Management Journal, 38, 317-321.

Kim, S., Hong, S., Magnusen, M. J., \& Rhee, Y. (2020). Hard knock coaching: a cross-cultural study of the effects of abusive leader behaviors on athlete satisfaction and commitment through interactional justice. International Journal of Sports Science \& Coaching, 15(5-6), 597-609. 
Kline, R. B. (1998). Principles and practice of structural equation modeling. New York: The Guilford Press.

Koo, G., \& Dittmore, S. W. (2014). Effects of intercollegiate athletics on private giving in higher education. Journal of Issues in Intercollegiate Athletics, 7, 1-16.

Mathieu, J., \& Zajac, D. (1990). A review and meta-analysis of the antecedents, correlates, and consequence of organizational commitment. Psychological Bulletin, 108(2), 171-194.

McGee, G. W., \& Ford, R. C. (1987). Two (or more?) dimensions of organizational commitment reexamination of the affective and continuance commitment scales. Journal of Applied Psychology, 72(5), 638-641.

Meyer, J. \& Allen, N. (1984). Testing the "side-bet theory" of organizational commitment: Some methodological considerations. Journal of Applied Psychology, 69(3), 372-278.

Meyer, J. P., \& Allen, N. J (1991). A three-component conceptualization of organizational commitment. Human Resource Management Review, 1(1), 61-89.

Meyer, J. P., \& Allen, N. J. (1997). Commitment in the workplace: Theory, research, and application. Thousand Oaks, CA: Sage.

Mowday, R. T., Porter, L. W., \& Steers, R.M. (1982). Employee-organization linkages: The psychology of commitment, absenteeism, and turnover. New York: Academic Press.

National Collegiate Athletic Association. (2010). History. Retrieved from http://www.ncaa.org/ wps/ wcm/connect/public/ncaa/about+the+ncaa/who +we+are/about+the+ncaa+history

Nunnally, J. C. (1978). Psychometric theory (2nd ed.). New York: McGraw-Hill.

O’Reilly III, C., \& Chatman, J. (1986). Organizational commitment and psychology attachment: The effects of compliance, identification, and internalization on prosocial behavior. Journal of Applied Psychology, 71(3), 492-499.

Palupi, D.A.P., Cahjono, M.P. and Satyawati, E. (2017).
Effect of leadership on the job satisfaction with organizational commitment and trust in leader as mediators. Review of Integrative Business and Economics Research, 6(4), 400-408.

Porter, L. W., Steer, R. M., Mowday, R. T., \& Boulian, P. V. (1974). Organizational commitment, job satisfaction, and turnover among psychiatric technicians. Journal of Applied Psychology, 59(3), 603-309.

Raedeke, T. D. (1997). Is athlete burnout more than just stress? A sport commitment perspective. Journal of Sport \& Exercise Psychology, 19, 396-417.

Riechers, A. (1985). A review and reconceptualization of organizational commitment. Academy of Management Review, 10(3), 456-476.

Robinson, G. M., Magnusen, M. J, \& Kim, J. M. (2019). The socially effective leader: Exploring the relationship between athletic director political skill and coach commitment and job satisfaction. International Journal of Sports Science \& Coaching, 14(2), 197-204.

Safa, M., Ali, M. H., \& Ismail, A. (2018). Affective organizational commitment as a mediating factor for the leader's support and organizational citizenship behavior. International Journal of Business and Management Science, 8(2), 213-239.

Singh, A., \& Gupta, B. (2015). Job involvement, organizational commitment, professional commitment, and team commitment. benchmarking: An International Journal, 22(6), 1192-1211.

Somers, M. (1993). A test of the relationship between affective and continuance commitment using non-recursive models. Journal of Occupational and Organizational Psychology, 66(2), 185-192.

Shagholi, R., Zabihi, M. R., Atefi, M., \& Moayedi, F. (2011). The consequences of organizational commitment in education. Procedia Social and Behavioral Sciences, 15, 246-250

Turner, B. A., \& Chelladurai, C. (2005). Organizational and occupational commitment, intention to leave, 
and perceived performance of intercollegiate coaches. Journal of Sport Management, 19, 193-211.

Vamover, E. T., \& DeBowes, M. M. (2013). The impact of intercollegiate athletics in higher education. Higher Education Politics \& Economics, 1(1), 29-44.

Wallace, J. E. (1997). Becker's side-bet theory of commitment revisited: Is it time for a moratorium or a resurrection? Human Relations, 50, 727-749.

Weight, E. A., Jensen, J. A., \& Osborne, B. (2020). The Globalization of Intercollegiate Athletics:
Challenges, Opportunities, and Advice for Those Seeking to Emulate the U.S. Model of College Sport. Journal of Global Sport Management, 5(1), $1-12$.

Winterstein, A. (1998). Organizational commitment among intercollegiate head athletic trainers: Examining our work environment. Journal of Athletic Training, 33(1), 54-61.

Yang, Q., \& Wei, H. (2018). The impact of ethical leadership on organizational citizenship behavior. Leadership and Organization Development Journal, 39(1), 100-113. 